\title{
The Hamster Circadian Rhythm System Includes Nuclei of the Subcortical Visual Shell
}

\author{
Elliott G. Marchant ${ }^{1}$ and L. P. Morin ${ }^{1,2}$ \\ ${ }^{1}$ Department of Psychiatry and Behavioral Sciences, and ${ }^{2}$ Graduate Program in Neurobiology and Behavior, State \\ University of New York, Stony Brook, New York 11794
}

The clock regulating mammalian circadian rhythmicity resides in the suprachiasmatic nucleus. The intergeniculate leaflet, a major component of the subcortical visual system, has been shown to be essential for certain aspects of circadian rhythm regulation. We now report that midbrain visual nuclei afferent to the intergeniculate leaflet are also components of the hamster circadian rhythm system.

Loss of connections between the intergeniculate leaflet and visual midbrain or neurotoxic lesions of pretectum or deep superior colliculus (but not of the superficial superior colliculus) blocked phase shifts of the circadian activity rhythm in response to a benzodiazepine injection during the subjective day. Such damage did not disturb phase response to a novel wheel stimulus. The amount of wheel running or open field locomotion were equivalent in lesioned and control groups after benzodiazepine treatment. Electrical stimulation of the deep superior colliculus, without its own effect on circadian rhythm phase, greatly attenuated light-induced phase shifts. Such stimulation was associated with increased FOS protein immunoreactivity in the suprachiasmatic nucleus. The results show that the circadian rhythm system includes the visual midbrain and distinguishes between mechanisms necessary for phase response to benzodiazepine and those for phase response to locomotion in a novel wheel. The results also refute the idea that benzodiazepine-induced phase shifts are the consequence of induced locomotion. Finally, the data provide the first indication that the visual midbrain can modulate circadian rhythm response to light. A variety of environmental stimuli may gain access to the circadian clock mechanism through subcortical nuclei projecting to the intergeniculate leaflet and, via the final common path of the geniculohypothalamic tract, from the leaflet to the suprachiasmatic nucleus.

Key words: hamster; circadian rhythm; superior colliculus; pretectum; intergeniculate leaflet; suprachiasmatic nucleus
The suprachiasmatic nucleus (SCN) contains a master circadian clock used for coordinating physiology and behavior with the external environment (Klein et al., 1991; Morin, 1994). Synchronization between internal rhythmicity and periodic environmental stimulation is accomplished by stimulus-induced modulation of circadian clock phase (Daan and Pittendrigh, 1976; Pittendrigh and Daan, 1976). The primary synchronizing stimulus of the environment is the daily photoperiod, which acts through the retina and retinohypothalamic tract (RHT) to set phase of the circadian clock. The classic "light-type" phase-response curve (Morin, 1994) consists of delay phase shifts during the early subjective night, advance shifts during the late subjective night, and no phase response during the subjective day.

A second group of synchronizing stimuli can also alter clock phase, but in a different manner. These stimuli, which include benzodiazepine treatment or locomotion induced by access to a novel wheel, elicit phase advances during the subjective day and phase delays during the subjective night (Turek and Losee-Olson, 1986; Mrosovsky and Salmon, 1987; Ebihara et al., 1988; Reebs and Mrosovsky, 1989; Mistlberger et al., 1991). Such phase shifts

\footnotetext{
Received April 21, 1999; revised Sept. 8, 1999; accepted Sept. 16, 1999.

This work was supported by National Institutes of Health Grant NS22168 (L.P.M.). E.G.M. and portions of this research were also supported by a grant from the United States Air Force Office of Scientific Research. We thank Jane Blanchard for her excellent continuing assistance and Beth McAvey for her help with surgery and electrical stimulations.

Correspondence should be addressed to Dr. Lawrence P. Morin, Department of Psychiatry, Health Science Center, State University of New York, Stony Brook, NY 11794. E-mail: 1morin@epo.som.sunysb.edu.

Copyright (C) 1999 Society for Neuroscience 0270-6474/99/1910482-12\$05.00/0
}

require an intact intergeniculate leaflet (IGL) (Johnson et al., 1988; Janik and Mrosovsky, 1994; Wickland and Turek, 1994). Direct access by the IGL to the SCN is through the geniculohypothalamic tract, the primary neuromodulator of which is neuropeptide Y (NPY) (Card and Moore, 1982, 1989; Harrington et al., 1985; Morin et al., 1992; Morin and Blanchard, 1995). Electrical (Rusak et al., 1989) or chemical (Johnson et al., 1989) stimulation of the IGL elicits phase responses that are similar to those occurring response to benzodiazepine, locomotion in a novel wheel, or direct application of NPY to the SCN (Albers and Ferris, 1984; Albers et al., 1984). The pattern of phase shifts elicited by these stimuli is called an "NPY-type" phase-response curve (Morin, 1991). Presumably, endogenous or exogenous activation of IGL neurons releases endogenous NPY from geniculohypothalamic tract terminals in the SCN, thereby modulating circadian rhythm phase (Biello et al., 1994).

The routes by which sensory information relating to the presence of benzodiazepine, or to locomotion during novel wheel access, gain entry to the circadian rhythm system are unknown. However, the IGL has reciprocal connections with virtually all tectal and pretectal nuclei of the subcortical visual shell (Morin and Blanchard, 1998a). Any one or more of these nuclei might respond to benzodiazepine or locomotion in a novel wheel and provide entrainment information to the SCN via the IGL. The tectum and pretectum are known to regulate orientation to novel stimuli, responsiveness to somatosensory and painful stimuli, and to contain moderately abundant benzodiazepine receptors (Rhoades, 1981a,b; Stein, 1984; Scardigli et al., 1990; Redgrave et al., 1996a,b; Morin and Blanchard, 1998b). In addition, nuclei of 
the subcortical visual shell have recently been implicated in the regulation of photically induced paradoxical sleep (Miller et al., 1998). Therefore, the primary goal of the present experiments was to determine whether nuclei in the subcortical visual shell contribute to hamster circadian rhythm regulation. Second, the experiments sought to determine whether or not locomotion is the critical variable that regulates phase response to both benzodiazepine treatment and to novel wheel access. Finally, given the fact that the subcortical visual nuclei have efferent connections with the IGL, we used electrical stimulation of the deep superior colliculus to examine the possibility that the visual midbrain might (1) directly modify circadian rhythm regulation, (2) modulate circadian rhythm phase response to light, or (3) alter lightinduced expression of FOS protein in nuclei of cells in the SCN.

\section{MATERIALS AND METHODS}

Male Syrian hamsters (90-100 gm; Charles River) were individually housed under a 14/10 hr light/dark (LD) photoperiod (lights on at 8:00 A.M. $)$ in clear plastic cages $(45 \times 20 \times 20 \mathrm{~cm})$ with food and water available ad libitum. After $\sim 3$ weeks acclimation, each animal was transferred to a translucent polypropylene cage of similar dimensions that contained a $17 \mathrm{~cm}$ diameter running wheel. Wheel-running activity was monitored continuously by computer and recorded in $5 \mathrm{~min}$ bins. Baseline levels of wheel running were collected for 10-14 d, then each animal received a $0.02 \mathrm{ml}$ subcutaneous injection of atropine sulfate (54 $\mathrm{mg} / \mathrm{ml}$; Phoenix Pharmaceutical, St. Joseph, MO) $30 \mathrm{~min}$ before being deeply anesthetized with sodium pentobarbital (Anpro Pharmaceutical, Arcadia, CA; $95 \mathrm{mg} / \mathrm{kg}$ body weight), and placed into a stereotaxic device. At the time of surgery, hamsters ranged in weight between 110 and $140 \mathrm{gm}$. The animal use protocol for this research was approved by the Institutional Animal Care and Use Committee of Stony Brook University.

Surgical procedures. Knife cuts (KC) were made bilaterally with a 0.25-mm-thick, 0.9-mm-wide stainless steel knife blade lowered into the brain at a $20^{\circ}$ angle $3.8 \mathrm{~mm}$ lateral to the midline, $0.7 \mathrm{~mm}$ caudal to the transverse suture, and $4.8 \mathrm{~mm}$ ventral to the dura. The knife was then slowly moved $5.1 \mathrm{~mm}$ caudally and withdrawn. Animals sustaining control cuts were treated in the same manner, but the knife was lowered only to a depth sufficient to cut the dura.

Bilateral lesions of the deep superior colliculus (DSC), superficial superior colliculus (SSC), and pretectum (PRT) were made with intracerebral injections of the excitatory amino acid NMDA $(0.6 \mu \mathrm{l}$ of $0.2 \mathrm{M}$ in saline per side; $0.2 \mu \mathrm{l}$ per min) via a $1 \mu \mathrm{l}$ Hamilton syringe inserted at a $20^{\circ}$ angle. Animals receiving control injections received equivalent procedures, but were injected into one of the three targets with vehicle only. After each injection, the needle was left in place for $5 \mathrm{~min}$ to minimize spread of the neurotoxin into the needle track. Coordinates for the deep superior colliculus lesions were $3.3 \mathrm{~mm}$ caudal to bregma, 2.4 $\mathrm{mm}$ lateral to midline, and $3.4 \mathrm{~mm}$ ventral to dura. Coordinates for the superficial superior colliculus lesions were $3.3 \mathrm{~mm}$ caudal to bregma, 2.4 $\mathrm{mm}$ lateral to midline, and $2.5 \mathrm{~mm}$ ventral to dura. Pretectal lesions were aimed at the nucleus of the optic tract [as defined by Morin and Blanchard (1998a)] with the intention of damaging adjacent nuclei. The coordinates were $1.9 \mathrm{~mm}$ caudal to bregma, $2.8 \mathrm{~mm}$ lateral to midline, and $3.5 \mathrm{~mm}$ ventral to dura.

Each animal that was to receive electrical stimulation was unilaterally implanted in the deep superior colliculus with twisted pair, insulated bipolar electrodes (MS303/3; Plastics One, Roanoke, VA) using the coordinates specified above for neurotoxic lesion of the same structure. Three small screws and dental acrylic (Dentsply, York, PA) anchored the electrodes to the skull.

Histology. Deeply anesthetized animals were perfused transcardially with physiological saline followed by $4 \%$ paraformaldehyde in $0.1 \mathrm{M}$ phosphate buffer with sodium $m$-periodate and lysine (McLean and Nakane, 1974). Each brain was removed and post-fixed overnight in the same solution. Brains were transferred to a phosphate buffer solution containing $30 \%$ sucrose for cryoprotection, frozen, and serially sectioned $(40 \mu \mathrm{m})$ in the coronal plane. Sections were collected in $0.01 \mathrm{M}$ PBS with $0.05 \%$ sodium azide. All immunohistochemistry was performed with free-floating sections using the ABC technique (Hsu et al., 1981) and diaminobenzidine (DAB) as the chromogen. The biotin-labeled secondary antibodies were of goat origin (Jackson ImmunoResearch, West
Grove, PA) and preabsorbed to minimize cross-reactivity. After a pretreatment in PBS with $3 \%$ hydrogen peroxide, tissue was incubated with the primary antibody for $2 \mathrm{~d}$ with $0.3 \%$ Triton X-100 and $3 \%$ goat serum (Jackson ImmunoResearch). Sections were rinsed and incubated in biotin-conjugated goat anti-rabbit IgG (Jackson ImmunoResearch) for $90 \mathrm{~min}$. After additional rinsing, tissue was incubated in avidin-biotin complex (Vector Laboratories, Burlingame, CA) for another $90 \mathrm{~min}$, then rinsed again and developed in DAB (50 mg in $100 \mathrm{ml}$ Tris, $\mathrm{pH} 7.4$ ).

Immunohistochemical procedures for FOS protein detection were similar except that an Elite ABC kit (Vector Laboratories) was used, and a nickel ammonium sulfate solution $(0.002 \%)$ was added to the DAB solution to intensify staining.

Lesion assessment. For the knife-cut brains, adjacent series of tissue were processed separately for immunoreactivity (IR) to NPY (rabbit antiserum; Peninsula Labs, Belmont, CA), glial fibrillary acidic protein (GFAP; rabbit antiserum; Dako, Carpinteria, CA), and CT- $\beta$ (goat antiserum; List, Campbell, CA). NPY-IR was specifically used to evaluate damage to the IGL, SCN, and certain IGL-pretectum connections. CT- $\beta$-IR was used to assess the extent to which retinal projections to the pretectum and tectum were damaged. Brains from the pretectum, deep superior colliculus, and superficial superior colliculus groups were evaluated using two series of tissue, one stained for NPY-IR and the other for GFAP-IR. GFAP-IR, as used in this study, indicates the presence of a class of astrocytes responding to local neural damage (Coyle et al., 1978; Morin et al., 1989), thereby providing an index of the regions with neuronal damage, likely cell death, and associated gliosis. Effective NMDA lesions typically create a zone of nearly total neuron loss grading to distal regions with no loss. This distance is related to site of injection and is modified by a variety of factors, including natural boundaries in the brain and the density of neurons for which NMDA is not neurotoxic (Coyle et al., 1978). Distal neurons at sites not directly contacted by the neurotoxin may also be destroyed (Schwob et al., 1980). Functionality of residual neurons in the vicinity of the site of neurotoxin injection cannot easily be ascertained.

Assessment of electrode placement. The sites of the electrode tips in the animals receiving electrical stimulation were determined from brains cut in $40 \mu \mathrm{m}$ sections and processed for FOS immunohistochemistry or from tissue sections stained with cresyl violet. Locations of the electrode tips were plotted on brain drawings made using a camera lucida with reference to an atlas of the hamster brain (L. Morin and R. Wood, unpublished observations).

Statistics. Statistical evaluations were performed with the CSS StatisticA (StatSoft) statistics package, version 4.5.

Counts of neuronal nuclei immunoreactive for FOS protein. FOSimmunoreactive neuronal nuclei were automatically counted by a computer-aided imaging device (MCID; Imaging Research, St. Catherine's, Ontario, Canada) with the experimenter blind to the stimulation procedures applied to the specific brain in which the FOS counts were made. A digitized low magnification, grayscale microscope image was obtained by a SONY XC-77 video camera and displayed on a computer monitor. A standard template was drawn for each of four bilateral levels in the mid-SCN region, three levels of the IGL, and two each of the dorsal raphe and median raphe nuclei. The templates were then applied to the corresponding tissue sections from the brain of each animal. The grayscale background within the template was digitally darkened until it could not be visually discriminated from foreground, then adjusted to be four grayscale levels lighter than foreground before the counts were made by the MCID device. This procedure produced reliable and repeatable counts of FOS-IR neuronal nuclei, which are reported as counts per square millimeter of tissue.

Phase-shift measurement. Phase responses to any of the several stimuli used in the present experiments were assessed by standard methods. Briefly, a straight line was fitted by eye through the onset of activity across $7-10$ circadian days before the day of stimulation and extrapolated forward to the day of stimulation. A straight line was also eye-fitted through a rhythmically stable series of 7-10 d of activity phase onsets after the day of stimulation, and this line was extrapolated backward to the day of stimulation.

The phase-shift magnitude and direction were obtained as the signed difference between the two phases of activity onset measured on the day of stimulation.

\section{EXPERIMENTAL PROCEDURES}

Table 1 shows the sequence of the experiments and the numbers of animals in each. 


\begin{tabular}{|c|c|c|c|c|c|}
\hline \multicolumn{6}{|l|}{ Experiment 1} \\
\hline Groups & $\mathrm{KC}$ & PRT NMDA & SSC NMDA & DSC NMDA & $\mathrm{CON}$ \\
\hline$(n)$ & $(16)$ & $(15)$ & $(14)$ & $(14)$ & $(34)$ \\
\hline Part A & \multicolumn{5}{|c|}{ Triazolam or $3 \mathrm{hr}$ novel wheel access beginning at CT6 in DD } \\
\hline Part B & \multicolumn{5}{|c|}{ Phase response to a $5 \mathrm{hr}$ compound stimulus beginning at CT6 in LL (same animals as in Part A) } \\
\hline Part C & \multicolumn{5}{|c|}{ General locomotion response to triazolam at CT6 in LL (subsets of four to five animals from each group in Part A) } \\
\hline \multicolumn{6}{|l|}{ Experiment 2} \\
\hline Groups & DSC NMDA & \multicolumn{4}{|l|}{$\mathrm{CON}$} \\
\hline$(n)$ & $(22)$ & \multicolumn{4}{|l|}{$(18)$} \\
\hline Part A & \multicolumn{5}{|c|}{ Phase-response curve to triazolam generated in DD (animals tested with and without triazolam in a crossover design) } \\
\hline Part B & \multicolumn{5}{|c|}{$\begin{array}{l}\text { Phase response to a } 5 \mathrm{hr} \text { dark or light compound stimulus in LL (groups divided; half get dark and half get light com- } \\
\text { pound stimulus) }\end{array}$} \\
\hline \multicolumn{6}{|l|}{ Experiment 3} \\
\hline Part A & \multicolumn{5}{|c|}{ Phase response to DSC electrical stimulation } \\
\hline Procedure & ES@ CT6 & ES@CT19 & CON@CT6 & CON@CT19 & \\
\hline$(n)$ & (9) & $(13)$ & $\begin{array}{l}\text { (each animal } \mathrm{r} \\
\text { crossover de }\end{array}$ & no stimulus cont & in a \\
\hline Part B & \multicolumn{5}{|c|}{ Phase response to light plus DSC electrical stimulation at CT19 } \\
\hline Procedure & \multicolumn{5}{|c|}{$\mathrm{ES}+$ light $\quad$ Light only } \\
\hline$(n)$ & \multicolumn{5}{|c|}{ (14) (Animals received each treatment in a crossover design) } \\
\hline Part C & \multicolumn{5}{|c|}{ FOS-IR induction by light and/or DSC electrical stimulation at CT19 } \\
\hline Group & Light & $\mathrm{ES}+$ light & ES & No light or ES & \\
\hline$(n)$ & $(4)$ & $(5)$ & $(4)$ & (4) (all animal & t B) \\
\hline
\end{tabular}

CON, Control; DSC, deep superior colliculus; ES, electrical stimulation; KC, knife cut; PRT, pretectum; SSC, superficial superior colliculus.

\section{Experiment 1. Part A: Effect of subcortical lesions on circadian rhythm phase response to triazolam or novel wheel access}

Lesion or control surgical procedures were conducted in mixed manner across an interval of several days. By experimental design, the control group (CON) included the 10, 9, 6, and 9 sham surgery animals corresponding to each of the four lesion groups, respectively. Approximately 4 weeks after surgery, all animals were simultaneously transferred into continuous dark (DD) and left undisturbed for 3-4 weeks. Each animal received, in a counterbalanced manner, a subcutaneous injection of triazolam (TZ; 5 $\mathrm{mg} / 0.2 \mathrm{ml}$ dimethylsulfoxide), a $0.2 \mathrm{ml}$ vehicle injection, or exposure to a "novel wheel." The novel wheel stimulus consisted of a clean, standard 17-cm-diameter running wheel enclosed in a clear Plexiglas container. Each animal was placed in the wheel from which it could not exit, and the wheel plus its enclosure was placed on the shelf next to the home cage for $3 \mathrm{hr}$. Wheel revolutions during novel wheel exposure were recorded by computer. All injections were at circadian time 6 (CT6; $6 \mathrm{hr}$ before normal activity onset), whereas the novel wheel procedure started at CT4. Approximately 2 wks after these manipulations were complete, all animals were returned to a 14/10 LD cycle for $30 \mathrm{~d}$ before being exposed to continuous light (LL; 25 lux).

\section{Experiment 1. Part B: Effect of subcortical lesions on circadian rhythm phase response to a $5 \mathrm{hr}$ compound stimulus}

When running rhythms of the animals in Part A were stable (at least $30 \mathrm{~d}$ in LL), phase response to a compound stimulus was conducted. The compound stimulus consisted of being placed in a novel wheel inside the plastic wheel enclosure, which was then transferred to a large, dark box along with three to five similarly treated animals. Exposure to the compound stimulus started at CT6 and lasted for $5 \mathrm{hr}$. At the end of this condition, each animal was returned to its home cage for an additional 2 week period in
LL. If the circadian locomotor rhythm of an animal in LL showed splitting or disorganization that interfered with phase measurements, it was removed from this part of the experiment.

\section{Experiment 1. Part C: Effect of subcortical lesions on general locomotor activity induced by TZ}

Subsets of animals randomly selected from the lesion and control groups used in Parts A and B were transferred to clear plastic cages without wheels and returned to a standard 14/10 LD photoperiod for 3-4 weeks. After this interval, a $5 \mathrm{mg}$ injection of TZ was given to half the animals at zeitgeber time $6 \mathrm{hr}$ (ZT 6), whereas the others received vehicle. Each animal was returned to its home cage, which was placed in a general activity monitor (San Diego Locomotor System, San Diego, CA). An index of distance traveled was obtained from the breakage of infrared beams during the $3 \mathrm{hr}$ test interval. All recording was conducted in darkness. The hamsters, still in their home cages, were then returned to the standard LD photoperiod for an additional 2 weeks, at which time the injection treatments were reversed, and the test was repeated in a counterbalanced manner.

After this experiment, all knife-cut and corresponding control animals were deeply anesthetized with pentobarbital and given 5 $\mu l$ bilateral intraocular injections of cholera toxin, $\beta$ fragment (CT- $\beta$; List Biological Laboratories, Campbell, CA; $0.2 \%$ in $2 \%$ DMSO and saline). Two days later, these and all other animals in the experiment were deeply anesthetized with pentobarbital in preparation for perfusion and histological analysis of the lesions.

\section{Experiment 2. Part A: Phase-response curve of animals sustaining deep superior colliculus lesions}

Preliminary analysis of circadian rhythm phase response in Experiment 1 showed that of the three neurotoxic lesion locations, those aimed at the deep superior colliculus most consistently attenuated phase shifts to TZ. Therefore, NMDA or control lesions of the deep superior colliculus were made in this experi- 
ment, as described above. The animals were transferred to DD $\sim 14 \mathrm{~d}$ later. Injections began after $14 \mathrm{~d}$ in DD, with drug $(5 \mathrm{mg}$ TZ) and vehicle (DMSO) treatments alternating. Each hamster received up to five sequential injections, but not more than three treatments with the same substance. In addition, all injections of a particular type (drug or vehicle) were administered at different circadian times to individual animals. As before, if the circadian time of injection or the onset of the activity phase of the circadian locomotor rhythm could not be reliably calculated for a given animal, the animal was excluded from the remainder of the experiment, although its data to that point contributed to the phase-response curve to TZ. At the completion of this experiment, all animals were placed in LL.

\section{Experiment 2. Part B: Effect of light or dark on phase response of deep superior colliculus-lesioned animals to $\mathbf{5} \mathrm{hr}$ novel wheel access}

In Experiment 1, Part B, animals were transferred from constant light to darkness during a test of phase response to a compound stimulus. The present experiment evaluated whether lighting during the test influences such phase response. When running rhythms were stable after at least $30 \mathrm{~d}$ of LL (25 lux), the animals from Part A were randomly divided into two groups. Half from each surgical condition (deep superior colliculus or control) received a $5 \mathrm{hr}$ stimulus beginning at CT6, consisting of being removed from the home cage, placed in a standard novel wheel, then moved with three to five other animals to the dark test chamber. The remaining animals received the same treatment, but the test chamber was illuminated (25 lux). After the stimulus, each animal was returned to its home cage and maintained in LL for 2 weeks to allow circadian phase assessment. This was followed by a second manipulation with each animal administered the treatment not previously received. Approximately 2 wks later, the animals were perfused for histology.

\section{Experiment 3. Part A: Effect of deep superior colliculus electrical stimulation on circadian rhythm phase}

Hamsters were implanted unilaterally with stimulating electrodes, the tips aimed at the deep superior colliculus, and allowed 14 postsurgical days of wheel running. At this time, each animal was removed from its cage, connected to a stimulating device (model S4 Square Wave Stimulator; Grass Instruments, Quincy, MA), and returned to its home cage with access to the running wheel blocked by a piece of Plexiglas. Each hamster received electrical stimulation or a control (no electrical stimulation) manipulation in a counterbalanced crossover design with $\sim 14 \mathrm{~d}$ between manipulations. Electrical or control stimulation occurred for $45 \mathrm{~min}$ beginning at CT6 or CT19. In each case, initial intensity of stimulation was set to $150 \mu \mathrm{A}$, then slowly adjusted upward until the animal exhibited behavioral "freezing", a form of defensive posturing known to be a consequence of deep superior colliculus electrical stimulation (Northmore et al., 1988). Final stimulation intensities ranged from 150 to $300 \mu \mathrm{A}$ and $6-16 \mathrm{~V}$ with frequency held at $20 \mathrm{~Hz}$.

\section{Experiment 3. Part B: Effect of deep superior colliculus electrical stimulation on circadian rhythm phase response to light}

Hamsters were implanted with stimulating electrodes unilaterally in the deep superior colliculus under surgical conditions similar to those in Part A. When wheel-running rhythms were stable in DD, half the animals were given manipulations at CT19, which consisted of electrical stimulation for $45 \mathrm{~min}$ beginning $15 \mathrm{~min}$ before a $15 \mathrm{~min}, 400$ lux light pulse. The remaining animals received the light stimulus alone. Approximately $15 \mathrm{~d}$ later, the treatments were reversed such that all animals received both treatments in a counterbalanced, crossover design. Three animals were excluded from the analysis because their running rhythms were unstable during one of the sequential tests.

\section{Experiment 3. Part C: Effect of deep superior colliculus electrical stimulation on light-induced FOS protein expression in the circadian system}

Two weeks after their last manipulation in Part B, all animals from that experiment were randomly assigned to one of the following treatment conditions: a 15 min 400 lux light pulse and no electrical stimulation; a 45 min electrical stimulation and no light; electrical stimulation plus the light pulse; or a control procedure with no electrical stimulation or light. Each animal was connected to the electrical stimulation device at CT18:45, returned to its home cage with access to its running wheel blocked, and administered the appropriate treatment. After the $45 \mathrm{~min}$ interval, animals were disconnected from the stimulation device and left undisturbed for $\sim 75 \mathrm{~min}$. At that time, each was deeply anesthetized with pentobarbital, perfused, and its brain was prepared for FOS protein immunohistochemistry.

\section{RESULTS}

\section{Experiment 1}

Histology

Damage caused by the knife cuts was evident in the lateral central thalamus, pretectum, and overlying hippocampus and cortex (Fig. $1 A$ ). At the rostral end, the knife cuts extended ventrally through the lateral dorsal thalamic nucleus and often impinged slightly on the juncture between the ventral and posterior thalamic nuclei. The cuts extended caudally, damaging the lateral posterior thalamic nucleus. If a cut was positioned more medially, the damage intruded on the pretectal posterior limitans nucleus; if positioned somewhat more laterally, the dorsal lateral geniculate nucleus was damaged. The caudal limit to the knife cut damage was level with the rostral aspect of the medial geniculate nucleus. The knife cut did not enter the superior colliculus or nuclei of the pretectum medial to the posterior limitans nucleus. Analysis of tissue immunoreacted for NPY-IR revealed that the knife cuts were sufficiently deep to sever most NPY-IR fibers in the superior thalamic radiation which are known to connect IGL and pretectum (Morin and Blanchard, 1995, 1997).

CT- $\beta$-IR fibers and terminals were very dense in the IGL, ventral lateral geniculate nucleus, and dorsal lateral geniculate nucleus, with a conspicuous reduction of retinal fibers in the optic tract and in innervation of the pretectal nuclei (Fig. $1 B$ ). Reduced numbers of CT- $\beta$-IR fibers and terminals were evident in the olivary, medial, and posterior pretectal nuclei. The amount was similar to what is seen in the ipsilateral pretectum after a unilateral eye injection in a normal animal (cf., Morin et al., 1992). CT- $\beta$-IR fibers and terminals were evident in the superior colliculus in most brains. However, they were typically found in small, fairly dense concentrations limited to the medial edge of the zonal and superficial gray layers of the superior colliculus (Fig. $1 B$ ). The residual retinal innervation of the midbrain visual nuclei appears to be derived from fibers diverging from the optic tract at a point just rostral to the knife cuts.

In the animals with deep superior colliculus lesions, lesion damage as indicated by GFAP-IR was evident as far rostral as the posterior pretectal nucleus. It extended caudally to, but did not 

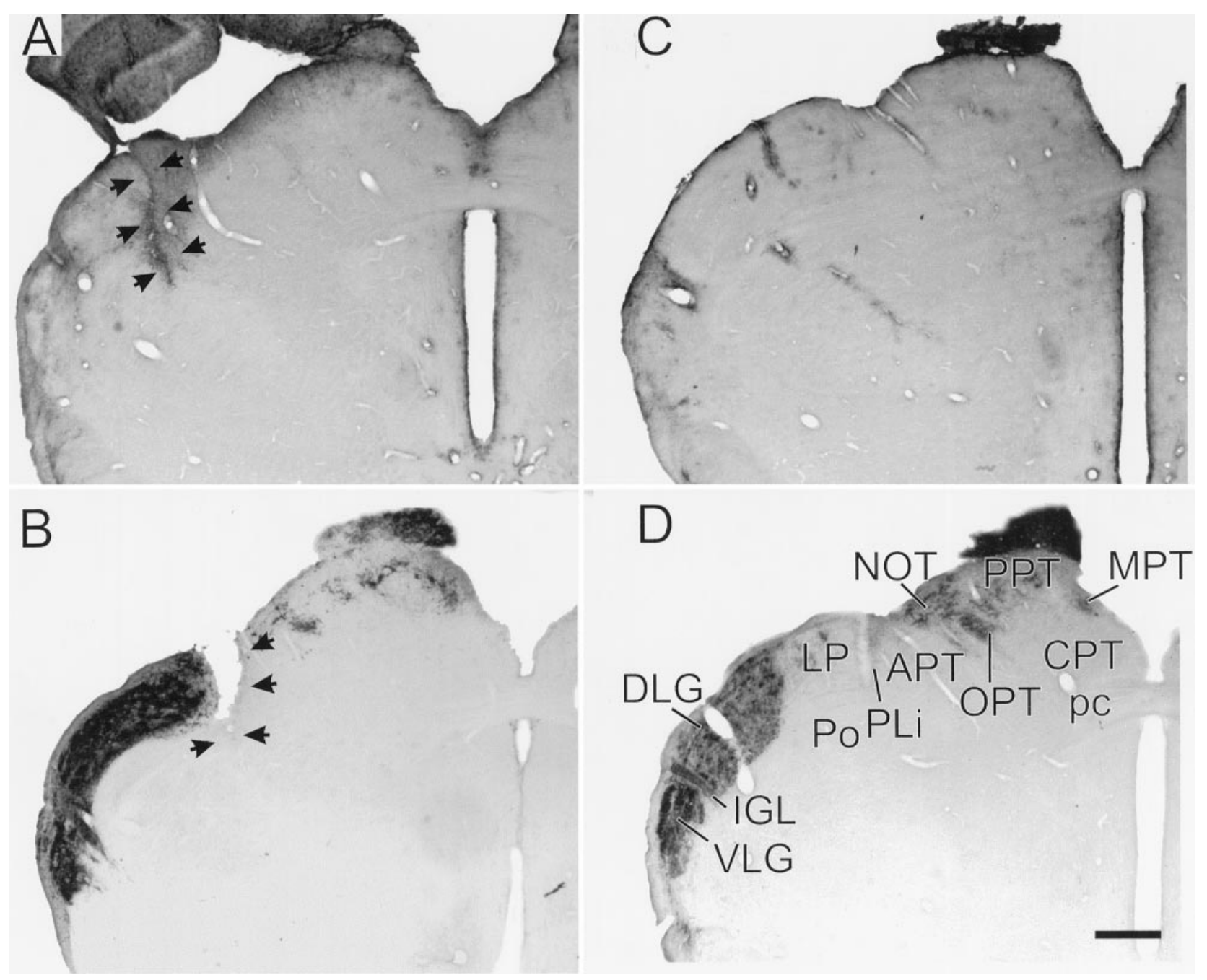

Figure 1. A, GFAP-IR identifying the scar (arrows) of a representative knife-cut thalamus between the dorsomedial dorsal lateral geniculate nucleus and the lateral posterior nucleus. $B$, CT- $\beta$-IR identifying visual projections in the lateral geniculate region, pretectum, and tectum of a representative hamster that received a knife cut (arrows) medial to the dorsal lateral geniculate nucleus. $C$, GFAP-IR in a control brain. The IGL is indicated by fairly dense GFAP-IR, as are numerous blood vessels. $D$, Normal visual projections identified with CT- $\beta$-IR in a control animal. In both $B$ and $D$, animals received bilateral intraocular injections of the tracer. Scale bar, $470 \mu \mathrm{m}$. $A P T$, Anterior pretectal nucleus; $C P T$, commissural pretectal nucleus; $D L G$, dorsal lateral geniculate; $I G L$, intergeniculate leaflet; $L P$, lateral posterior nucleus; $M P T$, medial pretectal nucleus; NOT, nucleus of the optic tract; $O P T$, olivary pretectal nucleus; $p c$, posterior commissure; $P L i$, posterior limitans nucleus; $P o$, posterior thalamic nucleus; $P P T$, posterior pretectal nucleus; $V L G$, ventral lateral geniculate.

include, the external cortex of the inferior colliculus. Damage typically did not extend laterally to the medial geniculate nucleus. In almost all cases, the cerebral aqueduct was enlarged, and the superior colliculus was greatly reduced in size (Fig. $2 A$ ). In most hamsters, the commissure of the superior colliculus was damaged as demonstrated by dense GFAP-IR. Three animals had incomplete lesions with one sustaining no apparent damage, one having a unilateral lesion, and one with damage only to the superficial superior colliculus. In addition, parts of the dorsal periaqueductal gray also sustained damage in some animals. All NMDA lesions, whether to deep superior colliculus, superficial superior colliculus, or pretectum, also caused damage to the hippocampus and, to a much lesser extent, somatosensory cortex.

The superficial superior colliculus-lesioned animals sustained less damage compared to the other animals with lesions (Fig. 2C). Damage was typically found only in the zonal and superficial gray layers of the superior colliculus in which there was a general reduction in size. In two brains, unilateral damage extended into the deeper layers of the superior colliculus. The superficial superior colliculus lesions were also associated with an enlarged cerebral aqueduct.

Lesions aimed at the pretectum (Fig. $3 A$ ) also damaged the lateral habenula, the anterior, dorsal, lateral dorsal, and lateral posterior thalamic nuclei, and in a few cases, the medial dorsal thalamic nucleus and dorsal lateral geniculate nucleus. Damage did not extend ventrally into the posterior thalamic nucleus in any brain. However, fairly extensive damage was evident in the rostral superficial, but not in more caudal or deep, superior colliculus. Pretectal lesions resulted in an enlarged cerebral aqueduct, with size of the rostral superior colliculus reduced and its shape distorted. Damage rarely extended into the posterior superior colliculus. Features common to the deep superior colliculus and pretectum lesions included damage to the rostral superficial superior colliculus and enlarged aqueduct. Deep superior colliculus lesions typically did not damage the pretectum.

There was no readily discernible evidence of damage to either 

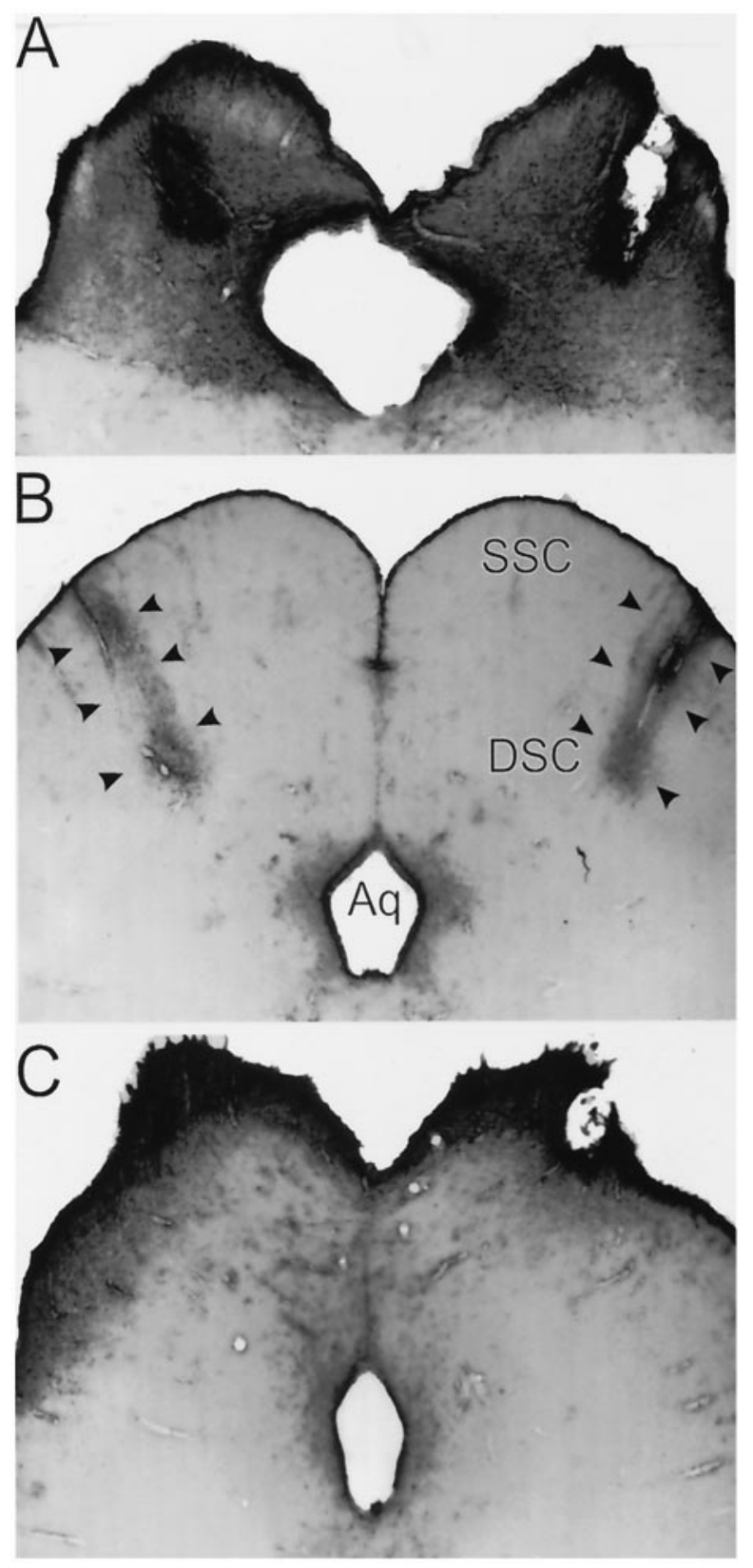

Figure 2. A, GFAP-IR in a representative brain of an animal sustaining bilateral NMDA-induced lesions of the deep superior colliculus. $B$, GFAP-IR in a control brain showing the dense immunoreactivity along the injection needle track (arrows). $C$, GFAP-IR in a representative brain of an animal sustaining bilateral NMDA-induced lesions of the superficial superior colliculus. Scale bar, $470 \mu \mathrm{m}$.

the IGL or SCN as a result of the knife cuts or neurotoxin injections into the pretectum, superficial superior colliculus, or deep superior colliculus. Judgements regarding the patency of the IGL and SCN were rendered after evaluation of cresyl violetstained CT- $\beta$-IR and NPY-IR material.

\section{Part $A$}

There was a significant effect of surgical treatment on circadian rhythm phase response to TZ (Figs. 4,$5 ; F_{(4,84)}=9.33 ; p<.001$ ). Post hoc analysis [Tukey's honest significant difference (HSD) test for unequal sample size] revealed significant differences between control and knife-cut groups $(p<0.003)$, control and deep
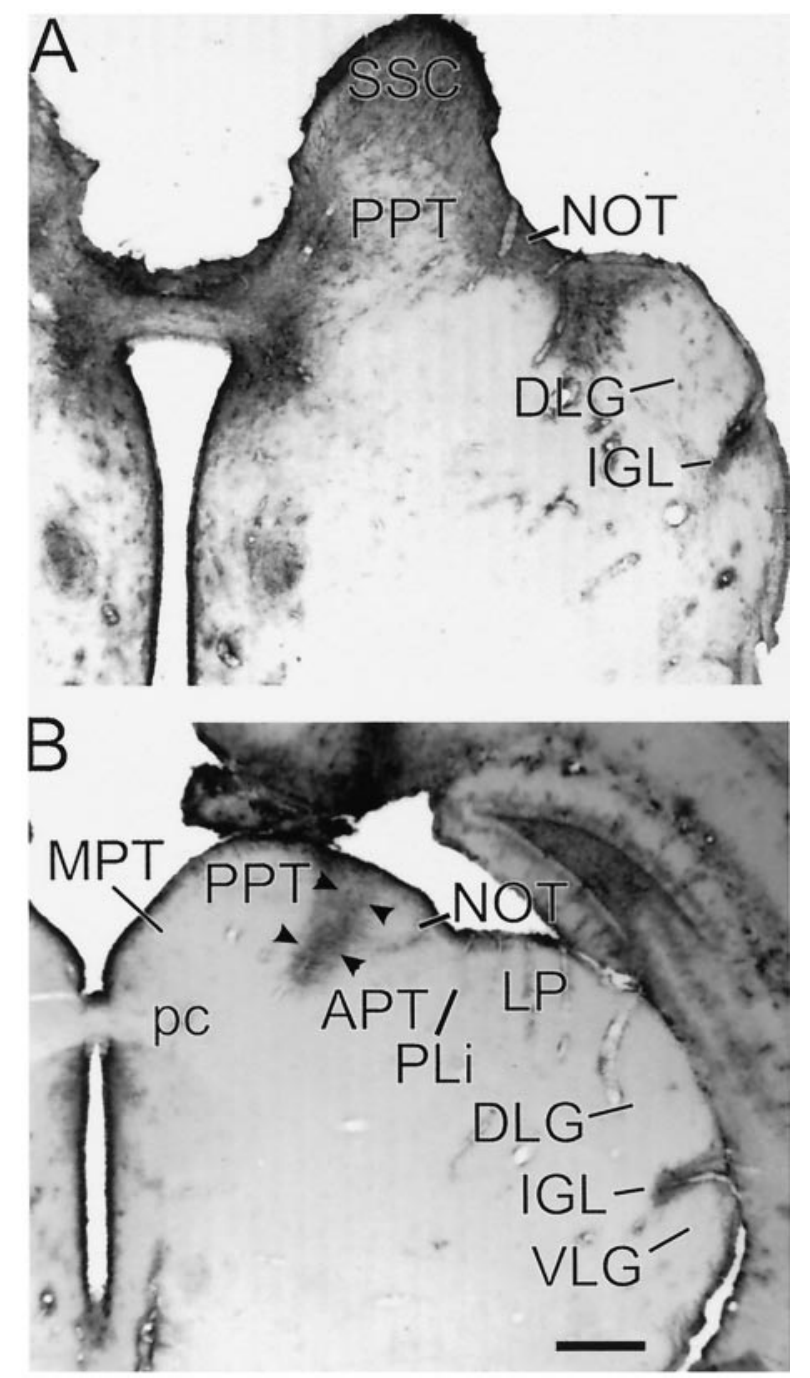

Figure 3. $A$, GFAP-IR in a representative brain of an animal sustaining bilateral NMDA-induced lesions of the pretectum. $B$, GFAP-IR in the brain of a control animal showing one of the bilateral needle tracks (arrows). Scale bar, $470 \mu \mathrm{m}$.

superior colliculus groups ( $p<0.001)$, and control and pretectum groups $(p<0.01)$, but phase response of the superficial superior colliculus group did not differ from the control group $(p<0.56)$. Two deep superior colliculus-lesioned animals with phase shifts $>0.5 \mathrm{hr}$ had small, incomplete lesions. When these animals were removed from the analysis, the mean phase shift by the deep superior colliculus-lesioned animals was $-0.20 \pm 0.11 \mathrm{hr}$. Among the pretectum hamsters, three shifted $>1 \mathrm{hr}$, and each was one of the animals sustaining incomplete lesions. The mean TZ-induced phase shift of the pretectum group with these animals removed from the calculations was $0.06 \pm 0.15 \mathrm{hr}$.

Access to a novel wheel for $3 \mathrm{hr}$ did not reliably induce phase shifts in control animals, and there was no main effect of this stimulus on phase response $\left(F_{(4,90)}=0.55 ; p<0.69\right)$. Only a small percentage of each group $(12.5,14,26,21$, and $26 \%$ for the knife-cut, deep superior colliculus, pretectum, superficial superior colliculus, and control lesion groups, respectively) phase-shifted $>0.5 \mathrm{hr}$ in response to novel wheel access. The percentages did not significantly differ between groups.

TZ administered at CT6 did not reliably induce wheel running. 


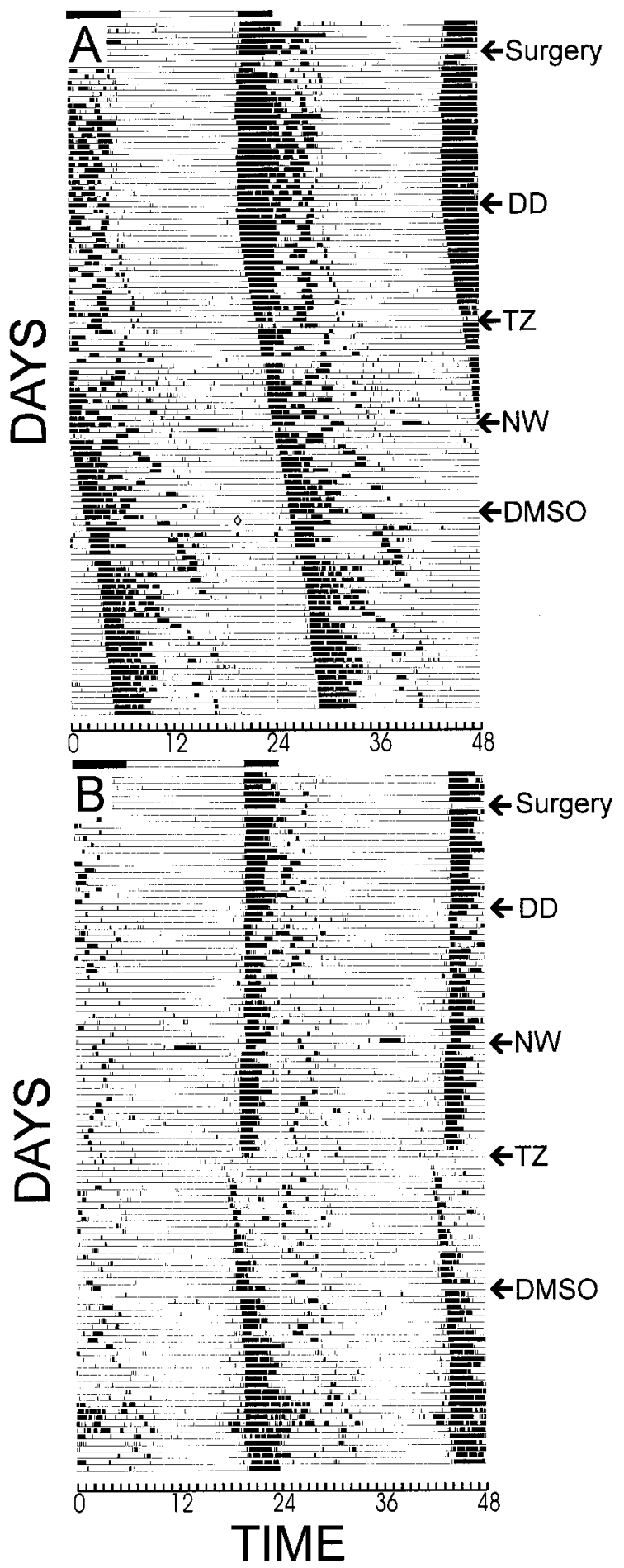

Figure 4. Running wheel records of typical constant dark-housed $(D D)$ animals that sustained $(A)$ a deep superior colliculus lesion or $(B)$ a control surgical procedure. A phase shift to triazolam $(T Z)$ was not shown by the lesioned animal, but was by the control animal. Neither shifted in response to either $3 \mathrm{hr}$ novel wheel access $(N W)$ or vehicle treatment (DMSO). See Results for further details.

Approximately $97 \%$ of treated animals across all groups generated $<100$ wheel counts during the $3 \mathrm{hr}$ measurement interval. However, despite the general failure to run in the wheel after a TZ injection, a nonparametric ANOVA (Kruskal-Wallis median test) revealed that drug treatment significantly increased the

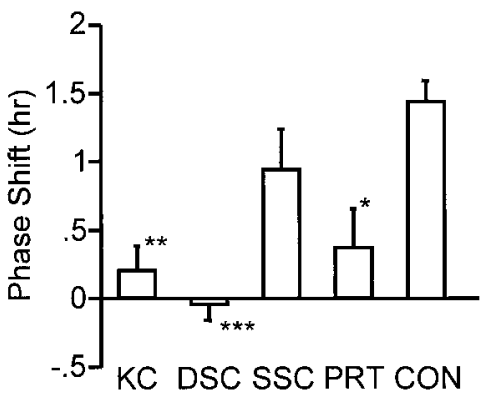

Figure 5. Mean ( $\pm \mathrm{SEM}$ ) phase-shift responses to $5 \mathrm{mg}$ triazolam at CT6 shown by of the groups sustaining knife cuts $(K C)$, neurotoxic lesions of the deep superior colliculus ( $D S C)$, superficial superior colliculus $(S S C)$, or pretectum $(P R T)$ or receiving a control procedure $(C O N) .{ }^{*} p<$ 0.01 versus controls; ${ }^{* *} p<0.003$ versus controls; ${ }^{* *} p<0.0001$ versus controls.



Figure 6. Mean ( \pm SEM) phase-shift responses to $5 \mathrm{hr}$ compound stimulus (novel wheel access in a dark box; see Materials and Methods, Experiment 1, Part B, for more detail) beginning at CT6. Each diamond indicates the response of a single individual in the groups sustaining knife cuts $(K C)$, neurotoxic lesions of the deep superior colliculus $(D S C)$, superficial superior colliculus $(S S C)$, or pretectum $(P R T)$ or receiving a control procedure $(C O N)$. There were was a significant main effect of surgical condition, but no group differed from any other group.

number of wheel revolutions $\left(\chi_{(4)}^{2}=14.49 ; p<0.006\right)$. In addition, the knife-cut group ran significantly less than the control group (Mann-Whitney $U$ test; $U=91.5 ; p<0.001$ ); there were no other between-group differences.

ANOVA also showed that circadian period in DD before the stimulus manipulations was not significantly altered by surgical treatment $\left(F_{(4,87)}=0.28 ; p<0.59\right)$.

\section{Part B}

When the animals used in Part A were subsequently tested with the $5 \mathrm{hr}$ compound stimulus provided at CT6, large phase advances were obtained (Fig. 6; overall mean $=4.15 \pm 0.24 \mathrm{hr}$ ). ANOVA revealed a significant effect of surgical condition on phase response $\left(F_{(4,75)}=2.73 ; p<0.03\right)$, but post hoc analysis with Tukey's HSD test for unequal sample sizes did not identify significant differences between any two groups.

The total number of wheel revolutions during the $5 \mathrm{hr}$ presentation of the compound stimulus did not vary across surgical treatment groups $\left(F_{(4,75)}=0.44 ; p<0.77\right)$. Mean revolutions per $5 \mathrm{hr}$ were $5632 \pm 617,7114 \pm 528,6891 \pm 923,6586 \pm 934$, and $6716 \pm 567$ for the knife-cut, deep superior colliculus, PRT, superficial superior colliculus, and control lesion groups, respectively. 


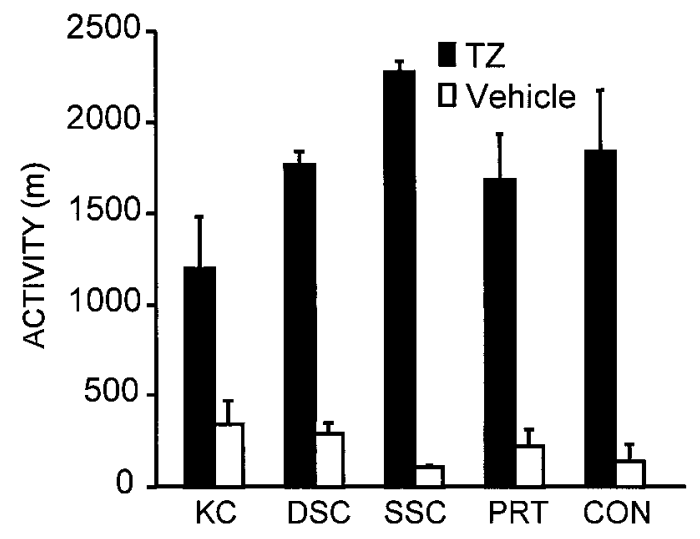

Figure 7. Mean ( \pm SEM) number of meters traveled by lesioned or control hamsters during a $3 \mathrm{hr}$ open field test after injection with $5 \mathrm{mg}$ triazolam or vehicle. There was a main effect of drug treatment and an interaction between drug and lesion type, but no between-group differences were significant (see Results). The surgical treatment groups sustained knife cuts $(K C)$, neurotoxic lesions of the deep superior colliculus $(D S C)$, superficial superior colliculus $(S S C)$, or pretectum $(P R T)$ or received a control procedure $(C O N)$.

\section{Part C}

TZ induced a large increase in general activity (in animals without wheel access) compared to vehicle treatment (Fig. 7; mean distance $=1753 \pm 199$ vs $\left.220 \pm 74 \mathrm{~m} ; F_{(1,31)}=113.03 ; p<0.001\right)$. There was also a modest, but significant, interaction between surgical treatment and drug exposure $\left(F_{(4,31)}=3.04 ; p<0.03\right)$ with the superficial superior colliculus animals having the greatest TZ-induced increase in activity while also having the lowest response to vehicle, and the knife-cut animals being least active in response to $\mathrm{TZ}$ while having the largest response to vehicle. Large increases in open field locomotion activity were observed in all surgical groups and were not related to a specific lesion type $\left(F_{(4,31)}=0.93 ; p<0.45\right)$, nor were there any significant differences between lesion groups indicated by the post hoc Tukey's HSD tests of open field activity in response to TZ.

\section{Experiment 2}

\section{Part $A$}

Damage to the brains of animals in the deep superior colliculus lesion group was comparable to that seen after the same treatment in Experiment 1. As before, the deep superior colliculus neurotoxin lesions reduced the volume of the superior colliculus, distorted it exterior boundaries, and enlarged the cerebral aqueduct. The caudal border of the posterior pretectal nucleus was damaged in many, but not all, of the cases. The commissural and medial pretectal nuclei as well as the commissure of the superior colliculus and the dorsal mesencephalic central gray were also damaged in a few animals. Ancillary damage to the hippocampus occurred in most lesioned brains. Four animals had partial lesions with one receiving only unilateral destruction and the others, a lesser degree of damage. The largest phase advance $(0.92 \mathrm{hr})$ by a neurotoxin-treated animal (given TZ at CT8) was obtained in one that had a partial lesion. Because not all animals were tested for phase shift responses to $\mathrm{TZ}$ at the same circadian times, this experiment did not allow any association between the extent of the lesion and magnitude of phase response to be determined.

Analysis of the phase-response curves revealed that only control animals appeared to have any systematic phase shifts in response to TZ given at the various circadian times (Fig. 8). All

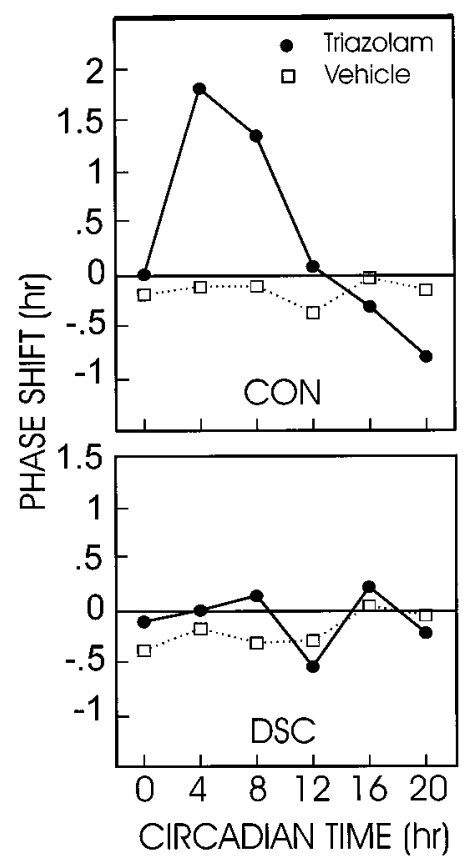

Figure 8. Phase-response curves of animals with deep superior colliculus lesions $(D S C)$ or control surgery $(C O N)$ given either triazolam or vehicle. The deep superior colliculus failed to exhibit circadian rhythm phase shifts in response to TZ or vehicle at any time tested. Control animals had a normal phase-response curve to TZ injections. See Results for the statistical analysis.

groups were tested simultaneously, but for the sake of graphical clarity, the data are presented in two panels of the figure. MannWhitney $U$ tests were used to compare phase shift magnitudes at $\mathrm{CT} 4, \mathrm{CT} 8$, and CT20 between all combinations of the experimental groups. Phase response by control animals to TZ administered at CT4 and CT8 was significantly greater than the response by each of the other three groups $(p<0.05 ; U \leq 4$ in each case). At CT20, control/TZ group differed significantly from the control/vehicle and deep superior colliculus/vehicle groups $(p<$ 0.05 ; $U \leq 4$ in each case), but not from the deep superior colliculus/TZ group.

\section{Part B}

The animals were the same as those used in Experiment 2A (see above for a description of the histology). There was a significant main effect of light (Fig. 9A) on phase response to $5 \mathrm{hr}$ novel wheel access $\left(F_{(1,11)}=9.45 ; p<0.01\right)$. The phase shifts of animals in the dark during wheel access were larger than those of animals in the light $(5.05 \pm 0.58$ vs $1.99 \pm 0.57 \mathrm{hr}$, respectively), but the magnitudes of the phase-shift responses were unaffected by lesion condition.

There was neither a main effect of lesion treatment or of light condition on the amount of running during the $5 \mathrm{hr}$ novel wheel access (Fig. 9B). However, there was a significant interaction between the lesion and light conditions $\left(F_{(1,9)}=16.89 ; p<0.002\right)$. In darkness, running by deep superior colliculus-lesioned animals did not differ from that by control animals ( $8514 \pm 1896$ vs $6558 \pm$ 1622), but deep superior colliculus-lesioned animals exposed to novel wheels for $5 \mathrm{hr}$ in the light ran significantly less than control animals (4025 \pm 411 vs $8151 \pm 181 ; p<0.04$; Tukey's HSD test). 

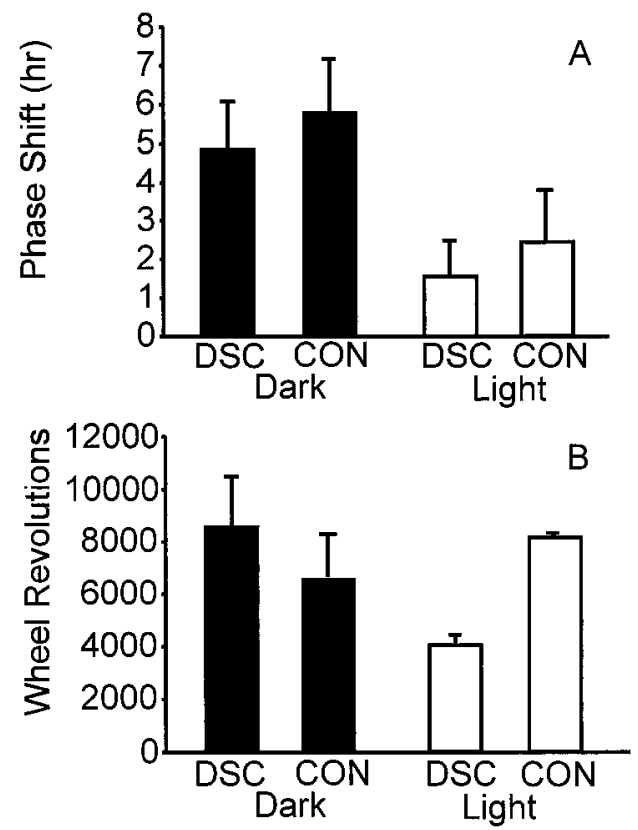

Figure 9. $A$, Mean ( \pm SEM) phase shifts of deep superior colliculus $(D S C)$ or control $(C O N)$-lesioned animals administered a $5 \mathrm{hr}$ compound stimulus in the dark or in the light. There was a main effect of lighting condition on phase response. $B$, Mean ( $\pm \mathrm{SEM}$ ) wheel revolutions during the $5 \mathrm{hr}$ compound stimulus. There was an interaction between lesion condition and lighting.

\section{Experiment 3}

\section{Part $A$}

Electrode placements were in the mid to caudal deep superior colliculus in all animals stimulated at CT6 or CT19. Electrical stimulation of the deep superior colliculus for $45 \mathrm{~min}$ induced average circadian rhythm phase shifts of $0.10 \pm 0.12$ and $0.08 \pm$ $0.14 \mathrm{hr}$ for animals stimulated at CT6 and CT19, respectively. These were not significantly different from the phase shifts by the same animals in response to sham electrical stimulation at the same circadian times.

\section{Part B}

Electrical stimulation of the deep superior colliculus greatly attenuated phase shifts induced by light. Light alone at CT19 elicited moderately large phase advances $(2.6 \pm 0.14 \mathrm{hr})$, whereas the average phase advance to the combined light plus simultaneous electrical stimulation was reduced by approximately 1.66 hr, a $64 \%$ decrease. This difference was statistically significant $(t$ test for dependent measures; $t=9.55$; df $=13$; $p<0.001$ ).

\section{Part $C$}

The animals in this experiment were also used in Part B. Histological analysis revealed that each had electrodes placed unilaterally in the caudal deep superior colliculus. Two-way ANOVA was used to evaluate the effects of the manipulation on counts of FOS-IR nuclei in the SCN, IGL, dorsal raphe and median raphe (Table 2). There were no interaction effects of light and electrical stimulation in any region. For the SCN (Fig. 10), IGL, and dorsal raphe, there were main effects of light $\left(F_{(1,13)}=98.76, p<0.001\right.$; $F_{(1,13)}=22.28, p<0.001$; and $F_{(1,13)}=6.85, p<0.02$, respectively) and of electrical stimulation $\left(F_{(1,13)}=15.03, p<0.001\right.$; $F_{(1,13)}=7.72, p<0.01$; and $F_{(1,13)}=10.83, p<0.005$, respec-
Table 2. Immunoreactive FOS nuclei in cells of several regions in the circadian rhythm system

\begin{tabular}{lrrlr} 
Treatment & \multicolumn{1}{c}{ SCN } & \multicolumn{1}{c}{ IGL } & \multicolumn{1}{l}{ DR } & \multicolumn{1}{c}{ MR } \\
\hline CON & $815 \pm 236$ & $88 \pm 42$ & $236 \pm 82$ & $85 \pm 28$ \\
Light & $2767 \pm 228$ & $374 \pm 44$ & $402 \pm 51$ & $168 \pm 33$ \\
ES & $1533 \pm 262$ & $269 \pm 78$ & $467 \pm 76$ & $305 \pm 93$ \\
Light + ES & $3628 \pm 150$ & $495 \pm 58$ & $806 \pm 192$ & $363 \pm 37$ \\
\hline
\end{tabular}

$\overline{\text { CON, No light, no electrical stimulation; ES, electrical stimulation; DR, dorsal }}$ raphe nucleus; IGL, intergeniculate leaflet; MR, median raphe nucleus; SCN, suprachiasmatic nucleus.

Mean $( \pm \mathrm{SE})$ counts $/ \mathrm{mm}^{2}$ tissue.

tively). For the median raphe, there was only a main effect of electrical stimulation $\left(F_{(1,13)}=14.12 ; p<0.002\right)$.

\section{DISCUSSION}

The primary contribution of the present work is to expand the definition of the "circadian visual system" to include midbrain nuclei of the subcortical visual shell. An important secondary result is the demonstration that neural circuitry regulating circadian rhythm phase response to benzodiazepines can be distinguished from that necessary for phase response to environmentally induced locomotion. Equally important are data supporting the view that cells in one or more mesencephalic nuclei of the subcortical visual system can modify circadian rhythm response to light.

\section{Structure and function of the circadian visual system}

With the description in 1972 of a robust, direct retinal projection to the hypothalamus, the SCN, primary target of the RHT (Hendrickson et al., 1972; Moore and Lenn, 1972), was established as the site in which circadian rhythmicity was likely to be both generated and entrained to the environmental photoperiod (Moore and Eichler, 1972; Stephan and Zucker, 1972; Rusak, 1977; Ralph et al., 1990). The concept of a "circadian visual system" (Morin, 1994) emerged from subsequent anatomical observations that the retinorecipient IGL of the lateral geniculate complex provides a major, NPY-containing projection to the SCN (Card and Moore, 1982; Moore and Card, 1983; Harrington et al., 1985; Morin et al., 1992; Morin and Blanchard, 1995, 1997).

Functional studies have shown that NPY acts on the SCN to regulate circadian rhythm phase (Albers and Ferris, 1984; Albers et al., 1984; Biello et al., 1994; Biello, 1995) and that the IGL mediates rhythm response to tonic light stimulation (Harrington and Rusak, 1986, 1988; Pickard et al., 1987; Edelstein and Amir, 1999). The diminished response of the circadian clock in IGLlesioned animals to tonic light stimulation, the phase-shifting effects of light (Johnson et al., 1989), benzodiazepines (Johnson et al., 1988; Biello et al., 1991) or environmentally induced locomotion (Janik and Mrosovsky, 1994; Wickland and Turek, 1994; Marchant et al., 1997) has been attributed to the explicit loss of the IGL and its NPY-containing geniculohypothalamic projection to the SCN. The present work demonstrates that large parasagittal cuts through the subcortical visual shell (Morin and Blanchard, 1997, 1998a) abolish circadian rhythm phase response to benzodiazepine. This, and the neurotoxic lesion data, are consistent with the view that one or more of the medial nuclei in the visual midbrain provide information to the IGL regarding the presence of benzodiazepine (Pinard et al., 1990; Morin and Blanchard, 1998b). 


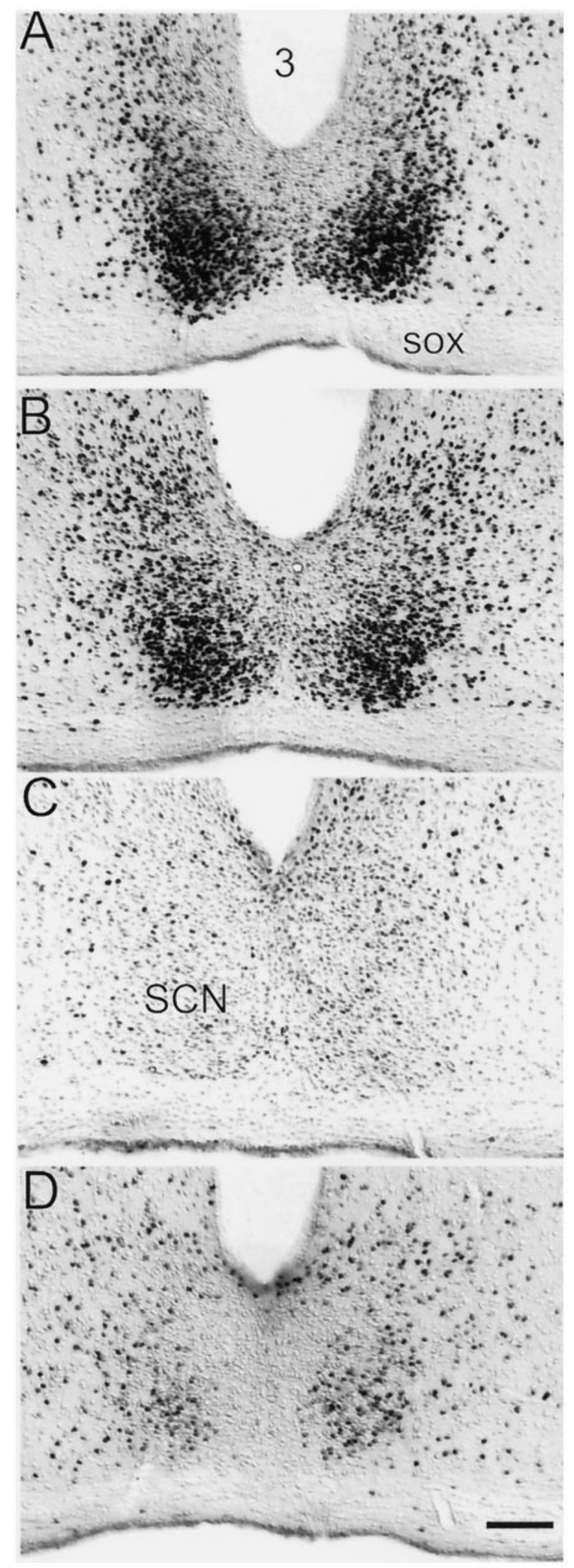

Figure 10. Immunoreactive FOS protein expression in representative suprachiasmatic nuclei $(S C N)$ of animals receiving simultaneous light exposure and electrical stimulation of the deep superior colliculus $(A)$, light plus sham electrical stimulation $(B)$, sham electrical stimulation and no light $(C)$, and no light plus electrical stimulation $(D)$. Electrical stimulation significantly augmented expression of FOS-IR. SOX, Supraoptic commissures; 3 , third ventricle.

\section{Independence of benzodiazepine- and locomotion-induced phase shifts}

Both triazolam, the benzodiazepine used in these studies, and locomotion induced by novel wheel access yield similar phaseresponse curves of the NPY-type (Turek and Losee-Olson, 1986; Mrosovsky et al., 1992). However, at the doses typically used in previous investigations, significant phase response to triazolam frequently has been associated with increased locomotion in an available running wheel or an open field (Mrosovsky and Salmon, 1990; Wickland and Turek, 1991). Despite significant evidence to the contrary (Mistlberger et al., 1991; Morin, 1991; Biello and Mrosovsky, 1993), this fact has been the cornerstone of the belief that all phase response to benzodiazepine is a consequence of drug-induced locomotion (Turek, 1989; Moore and Card, 1994; Mrosovsky, 1996).

The argument for causal similarity of phase response to the two stimulus types has been buttressed by the fact that each requires an intact IGL to stimulate phase shifts (Johnson et al., 1988; Biello et al., 1991; Janik and Mrosovsky, 1994; Wickland and Turek, 1994; Marchant et al., 1997). An alternative view, supported by the present data, is that phase response to benzodiazepine acts through a visual midbrain nucleus, whereas novel wheel-related locomotion acts elsewhere at a presently unknown location. Neural correlates of each stimulus type would be transmitted to the IGL with the geniculohypothalamic tract providing a "final common path" to the circadian clock in the SCN. Thus, depending on the ecological requirements of a given species, the geniculohypothalamic tract might transmit information about any of a variety of midbrain-mediated stimuli, such as pain, limb movements, or sound (Tiao and Blakemore, 1976; Finley et al., 1981; Rhoades, 1981a; Stein, 1984; Ledoux et al., 1985; Rees and Roberts, 1993) to the circadian clock.

\section{Midbrain regulation of phase response to light}

Light is a special stimulus class having direct access to the SCN, IGL, all nuclei of the pretectum, and to the tectum (Morin, 1994; Morin and Blanchard, 1997). The present results show that electrical stimulation of the deep superior colliculus during the subjective night attenuates light-induced phase shifts. Typically, the rhythm-related effects of the IGL are thought to be mediated by NPY release from geniculohypothalamic tract terminals in the SCN, with the major result of such release being phase advances during the midsubjective day (Albers and Ferris, 1984; Albers et al., 1984; Biello et al., 1994). Electrical or chemical stimulation of the IGL also elicits phase advances during the subjective day (Johnson et al., 1989; Rusak et al., 1989), presumably via the acute release of NPY from geniculohypothalamic tract terminals. Electrical stimulation of the deep superior colliculus did not induce phase shifts either during the subjective day or night. Therefore, it is unlikely that the deep superior colliculus contribution to circadian rhythm regulation is simply via excitation of NPY-containing neurons of the IGL and consequent release of NPY from geniculohypothalamic tract terminals in the SCN.

Lesions of the IGL have several effects on hamster rhythm response to light. Of these, the most robust is the failure of the circadian locomotor rhythm period to lengthen in constant light (Harrington and Rusak, 1986; Pickard et al., 1987), a "tonic" effect of light. In the present studies, loss of the midbrain visual nuclei did not modify normal circadian rhythm expression in constant darkness. However, the effects of constant light were not tested, and it remains to be determined whether or not lesions of 
the visual midbrain mimic the effects of IGL lesions on circadian period response to constant light.

Electrical stimulation of the midbrain raphe nuclei both attenuates light-induced FOS protein in SCN neurons (MeyerBernstein and Morin, 1999) and light-induced circadian rhythm phase shifts (Weber et al., 1998). Thus, we expected that electrical stimulation of the deep superior colliculus, which attenuates phase response to a light pulse, would also attenuate expression of light-induced FOS in SCN neurons. The data show that electrical stimulation actually increased FOS expression in the SCN, regardless of the lighting conditions. Although this result says little about the mechanism by which electrical stimulation attenuates light-induced phase shifts, it does provide direct evidence that information regarding the stimulation reached the SCN. The result also supports a previous observation that the number of countable SCN cells expressing FOS protein can, under certain circumstances, increase without being associated with a concomitant phase shift (Colwell et al., 1990). Previously, classes of nonphotic stimuli presumed to act through the IGL were shown to elicit phase shifts without inducing any change in FOS-IR of SCN neuronal nuclei (Janik and Mrosovsky, 1992; Mead et al., 1992; Cutrera et al., 1993; Zhang et al., 1993). The induction of FOS-IR expression in the SCN by electrical stimulation of the hamster deep superior colliculus does not result from a direct connection between the two nuclei (Morin et al., 1994; Morin and Blanchard, 1998a).

\section{Effectiveness of the nonphotic stimuli}

An unexpected result of the present investigation was the relatively poor phase-shift response to novel wheel-induced locomotion. Previous reports have emphasized the reliability of the method and the magnitude of consequent phase shifts (Mrosovsky, 1995, 1996). However, only $\sim 20 \%$ of control animals had phase shifts of $>30 \mathrm{~min}$ in the present study. The low percentage is consistent with previous observations in this laboratory (Meyer-Bernstein and Morin, 1998) and eliminates the possibility of definitive statements regarding whether or not a particular lesion blocks phase shifts to locomotion induced by novel wheel access. However, we believe that such a conclusion is warranted because of the similar proportions of all experimental groups showing phase shifts to the novel wheel stimulus.

In contrast to the effects of simple novel wheel-induced locomotion, the compound stimulus was extremely potent with $\sim 93 \%$ of controls shifting for $>30 \mathrm{~min}$. In addition, the average phase shift by the sham-lesioned animals was above expectation, with shifts by several animals being well in excess of normal. No lesion type attenuated phase response to the compound stimulus, either with respect to the percentage of animals phase shifting or phaseshift magnitude. In fact, the animals sustaining knife cuts actually had greater phase shifts than controls without sustaining an associated increase in wheel running.

\section{Conclusion}

The primary result of the present studies is a demonstration that the hamster midbrain contributes to the regulation of circadian rhythmicity. This regulation is related to both nonphotic and photic forms of time-giving stimuli. Moreover, the midbrain contributes to the regulation of circadian rhythm phase response to at least one class of nonphotic stimuli, but not to such regulation by another class of nonphotic stimuli. The data extend and amplify the definition of the "circadian visual system" and suggest that a variety of stimuli may act through the geniculohypothalamic tract, the final common pathway between the IGL and SCN, to modify circadian rhythm phase.

\section{REFERENCES}

Albers HE, Ferris CF (1984) Neuropeptide Y: role in light-dark entrainment of hamster circadian rhythms. Neurosci Lett 50:163-168.

Albers HE, Ferris CF, Leeman SE, Goldman BD (1984) Avian pancreatic polypeptide phase shifts hamster circadian rhythms when microinjected into the suprachiasmatic region. Science 223:833-835.

Biello SM (1995) Enhanced photic phase shifting after treatment with antiserum to neuropeptide Y. Brain Res 673:25-29.

Biello SM, Mrosovsky N (1993) Circadian phase-shifts induced by chlordiazepoxide without increased locomotor activity. Brain Res 622:58-62.

Biello SM, Harrington ME, Mason R (1991) Geniculo-hypothalamic tract lesions block chlordiazepoxide- induced phase advances in Syrian hamsters. Brain Res 552:47-52.

Biello SM, Janik D, Mrosovsky N (1994) Neuropeptide Y and behaviorally induced phase shifts. Neuroscience 62:273-279.

Card JP, Moore RY (1982) Ventral lateral geniculate nucleus efferents to the rat suprachiasmatic nucleus exhibit avian pancreatic polypeptidelike immunoreactivity. J Comp Neurol 206:390-396.

Card JP, Moore RY (1989) Organization of lateral geniculatehypothalamic connections in the rat. J Comp Neurol 284:135-147.

Colwell CS, Ralph MR, Menaker M (1990) Do NMDA receptors mediate the effects of light on circadian behavior. Brain Res 523:117-120.

Coyle JT, Molliver ME, Kuhar M (1978) In situ injection of kainic acid: a new method for selectively lesioning neuronal cell bodies while sparing axons of passage. J Comp Neurol 180:301-324.

Cutrera RA, Kalsbeek A, Pévet P (1993) No triazolam-induced expression of Fos protein in raphe nuclei of the male Syrian hamster. Brain Res 602:14-20.

Daan S, Pittendrigh CS (1976) A functional analysis of circadian pacemakers in nocturnal rodents. II. The variability of phase response curves. J Comp Physiol 106:253-266.

Ebihara S, Goto M, Oshima I (1988) Different responses of the circadian system to GABA-active drugs in two strains of mice. J Biol Rhythms 3:357-364.

Edelstein K, Amir S (1999) The role of the intergeniculate leaflet in entrainment of circadian rhythms to a skeleton photoperiod. J Neurosci 19:372-380.

Finley JCW, Maderdrut JL, Petrusz P (1981) The immunocytochemical localization of enkephalin in the central nervous system of the rat. J Comp Neurol 198:541-565.

Harrington ME, Nance DM, Rusak B (1985) Neuropeptide Y immunoreactivity in the hamster geniculo-suprachiasmatic tract. Brain Res Bull 15:465-472.

Harrington ME, Rusak B (1986) Lesions of the thalamic intergeniculate leaflet alter hamster circadian rhythms. J Biol Rhythms 1:309-325.

Harrington ME, Rusak B (1988) Ablation of the geniculo-hypothalamic tract alters circadian activity rhythms of hamsters housed under constant light. Physiol Behav 42:183-189.

Hendrickson AE, Wagoner N, Cowan WM (1972) An autoradiographic and electron microscopic study of retinohypothalamic connections. Zeitschrift fur Zellforschung 135:1-26.

Hsu S-M, Raine L, Fanger H (1981) Use of avidin-biotin-perioxidase complex $(\mathrm{ABC})$ in immunoperioxidase techniques: a comparison between $\mathrm{ABC}$ and unlabeled antibody (PAP) procedures. J Histochem Cytochem 29:577-580.

Janik D, Mrosovsky N (1992) Gene expression in the geniculate induced by a nonphotic circadian phase shifting stimulus. NeuroReport 3:575-578.

Janik D, Mrosovsky N (1994) Intergeniculate leaflet lesions and behaviorally-induced shifts of circadian rhythms. Brain Res 651:174-182.

Johnson RF, Smale L, Moore RY, Morin LP (1988) Lateral geniculate lesions block circadian phase shift responses to a benzodiazepine. Proc Natl Acad Sci USA 85:5301-5304.

Johnson RF, Moore RY, Morin LP (1989) Lateral geniculate lesions alter activity rhythms in the hamster. Brain Res Bull 22:411-422.

Klein DC, Moore RY, Reppert SM (1991) Suprachiasmatic nucleus: the mind's clock. New York: Oxford UP.

Ledoux JE, Ruggiero DA, Reis DJ (1985) Projections to the subcortical forebrain from anatomically defined regions of the medial geniculate body in the rat. J Comp Neurol 242:182-213. 
Marchant EG, Watson NV, Mistlberger RE (1997) Both neuropeptide Y and serotonin are necessary for entrainment of circadian rhythms in mice by daily treadmill running schedules. J Neurosci 17:7974-7987.

McLean IW, Nakane PK (1974) Periodate-lysine-paraformaldehyde fixative: a new fixative for immunoelectron microscopy. J Histochem Cytochem 22:1077-1083.

Mead S, Ebling FJP, Maywood ES, Humby T, Herbert J, Hastings MH (1992) A nonphotic stimulus causes instantaneous phase advances of the light-entrainable circadian oscillator of the Syrian hamster but does not induce the expression of $c$-fos in the suprachiasmatic nuclei. J Neurosci $12: 2516-2522$.

Meyer-Bernstein EL, Morin LP (1998) Destruction of serotonergic neurons in the median raphe nucleus blocks circadian rhythm phase shifts to triazolam, but not to novel wheel access. J Biol Rhythms 13:494-505.

Meyer-Bernstein EL, Morin LP (1999) Electrical stimulation of the median or dorsal raphe nuclei reduces light-induced FOS protein in the suprachiasmatic nucleus and causes circadian activity rhythm phase shifts. Neuroscience 91:81-105.

Miller AM, Obermeyer WH, Behan M, Benca RM (1998) The superior colliculus-pretectum mediates the direct effects of light on sleep. Proc Natl Acad Sci USA 95:8957-8962.

Mistlberger RE, Houpt TA, Moore-Ede MC (1991) The benzodiazepine triazolam phase-shifts circadian activity rhythms in a diurnal primate, the squirrel monkey (Saimiri sciureus). Neurosci Lett 124:27-30.

Moore RY, Card JP (1983) Visual pathways and the entrainment of circadian rhythms. Ann NY Acad Sci 453:123-133.

Moore RY, Card JP (1994) Intergeniculate leaflet: an anatomically and functionally distinct subdivision of the lateral geniculate complex. J Comp Neurol 344:403-430.

Moore RY, Eichler VB (1972) Loss of a circadian adrenal corticosterone rhythm following suprachiasmatic lesions in the rat. Brain Res 42:201-206.

Moore RY, Lenn NJ (1972) A retinohypothalamic projection in the rat. J Comp Neurol 146:1-14.

Morin LP (1991) Neural control of circadian rhythms as revealed through the use of benzodiazepines. In: Suprachiasmatic nucleus. The mind's clock. (Klein DC, Moore RY, Reppert SM, eds), pp 324-338. New York: Oxford UP.

Morin LP (1994) The circadian visual system. Brain Res Rev 67:102-127.

Morin LP, Blanchard JH (1995) Organization of the hamster intergeniculate leaflet: NPY and ENK projections to the suprachiasmatic nucleus, intergeniculate leaflet and posterior limitans nucleus. Vis Neurosci 12:57-67.

Morin LP, Blanchard JH (1997) Neuropeptide Y and enkephalin immunoreactivity in retinorecipient nuclei of the hamster pretectum and thalamus. Vis Neurosci 14:765-777.

Morin LP, Blanchard JH (1998a) Interconnections among nuclei of the subcortical visual shell: the intergeniculate leaflet is a major constituent of the hamster subcortical visual system. J Comp Neurol 396:288-309.

Morin LP, Blanchard JH (1998b) Distribution of GABA neurons and GABA/benzodiazepine receptor in the hamster circadian and subcortical visual systems. Soc Neurosci Abstr 24:1918.

Morin LP, Blanchard JH, Moore RY (1992) Intergeniculate leaflet and suprachiasmatic nucleus organization and connections in the hamster. Vis Neurosci 8:219-230.

Morin LP, Johnson RF, Moore RY (1989) Two brain nuclei regulating circadian rhythms are identified by GFAP immunoreactivity in hamsters and rats. Neurosci Lett 99:55-60.

Morin LP, Goodless-Sanchez N, Smale L, Moore RY (1994) Projections of the suprachiasmatic nuclei, subparaventricular zone and retrochiasmatic area in the golden hamster. Neuroscience 61:391-410.

Mrosovsky N (1995) A non-photic gateway to the circadian clock of hamsters. In: Circadian clocks and their adjustment, Ciba foundation symposium 183 (Chadwick DJ, Ackrill K, eds), pp 154-167. Chichester, UK: Wiley.

Mrosovsky N (1996) Locomotor activity and non-photic influences on circadian clocks. Biol Rev Camb Philos Soc 71:343-372.

Mrosovsky N, Salmon PA (1987) A behavioural method for accelerating re-entrainment of rhythms to new light-dark cycles. Nature 330:372-373.

Mrosovsky N, Salmon PA (1990) Triazolam and phase-shifting acceleration re-evaluated. Chronobiol Int 7:35-41.
Mrosovsky N, Salmon PA, Menaker M, Ralph MR (1992) Nonphotic phase shifting in hamster clock mutants. J Biol Rhythms 7:41-49.

Northmore DPM, Levine ES, Schneider GE (1988) Behavior evoked by electrical stimulation of the hamster superior colliculus. Exp Brain Res 73:595-605.

Pickard GE, Ralph MR, Menaker M (1987) The intergeniculate leaflet partially mediates effects of light on circadian rhythms. J Biol Rhythms 2:35-56.

Pinard R, Richards JG, Lanoir J (1990) Subcellular localization of $\mathrm{GABA}_{\mathrm{A}} /$ benzodiazepine receptor-like immunoreactivity in the superficial gray layer of the rat superior colliculus. Neurosci Lett 120:212-216.

Pittendrigh CS, Daan S (1976) A functional analysis of circadian pacemakers in nocturnal rodents. IV. Entrainment: Pacemaker as clock. J Comp Physiol 106:291-331.

Ralph MR, Foster RG, Davis FC, Menaker M (1990) Transplanted suprachiasmatic nucleus determines circadian period. Science 247:975-978.

Redgrave P, McHaffie JG, Stein BE (1996a) Nociceptive neurones in rat superior colliculus. I. Antidromic activation from the contralateral predorsal bundle. Exp Brain Res 109:185-196.

Redgrave P, Simkins M, McHaffie JG, Stein BE (1996b) Nociceptive neurones in rat superior colliculus. II. Effects of lesions to the contralateral descending output pathway on nocifensive behaviours. Exp Brain Res 109:197-208.

Reebs SG, Mrosovsky N (1989) Effects of induced wheel running on the circadian activity rhythms of Syrian hamsters: entrainment and phase response curve. J Biol Rhythms 4:39-48.

Rees H, Roberts MHT (1993) The anterior pretectal nucleus: a proposed role in sensory processing. Pain 53:121-135.

Rhoades RW (1981a) Organization of somatosensory input to the deep collicular laminae in hamster. Behav Brain Res 3:201-222.

Rhoades RW (1981b) Cortical and spinal somatosensory input to the superior colliculus in the golden hamster: an anatomical and electrophysiological study. J Comp Neurol 195:415-432.

Rusak B (1977) The role of the suprachiasmatic nuclei in the generation of circadian rhythms in the golden hamster, Mesocricetus auratus. J Comp Physiol 118:145-164.

Rusak B, Meijer JH, Harrington ME (1989) Hamster circadian rhythms are phase-shifted by electrical stimulation of the geniculo-hypothalamic tract. Brain Res 493:283-291.

Scardigli P, Fabre J-C, Thinus-Blanc C (1990) The effects of superior colliculus lesions on reactions to novelty in the hamster. Behav Brain Res 36:27-32.

Schwob JE, Fuller T, Price JL, Olney JW (1980) Widespread patterns of neuronal damage following systemic or intracerebral injections of kainic acid: a histological study. Neuroscience 5:991-1014.

Stein BE (1984) Multimodal representation in the superior colliculus and optic tectum. In: Comparative neurology of the optic tectum. (Vanegas H, ed), pp 819-841. New York: Plenum.

Stephan FK, Zucker I (1972) Circadian rhythms in drinking behavior and locomotor activity of rats are eliminated by hypothalamic lesions. Proc Natl Acad Sci USA 69:1583-1586.

Tiao Y-C, Blakemore C (1976) Functional organization in the visual cortex of the golden hamster. J Comp Neurol 168:459-482.

Turek FW (1989) Effects of stimulated physical activity on the circadian pacemaker of vertebrates. J Biol Rhythms 4:135-147.

Turek FW, Losee-Olson S (1986) A benzodiazepine used in the treatment of insomnia phase-shifts the mammalian circadian clock. Nature 321:167-168.

Weber ET, Cato MJ, Rea MA (1998) Electrical stimulation of the median or dorsal raphe nuclei modulate light-induced phase shifts of the circadian wheel-running rhythm of hamsters. Soc Res Biol Rhythms 6:134.

Wickland CR, Turek FW (1991) Phase-shifting effects of acute increases in activity on circadian locomotor rhythms in hamsters. Am J Physiol 261:R1109-R1117.

Wickland C, Turek FW (1994) Lesions of the thalamic intergeniculate leaflet block activity-induced phase shifts in the circadian activity rhythm of the golden hamster. Brain Res 660:293-300.

Zhang Y, Van Reeth O, Zee PC, Takahashi JS, Turek FW (1993) Fos protein expression in the circadian clock is not associated with phase shifts induced by a nonphotic stimulus, triazolam. Neurosci Lett 164: 203-208. 